\title{
Use of the polar coordinates technique to study interactions among professional Soccer players
}

\section{Carlos Lago Peñas}

Facultad de CC. de la Educación

Universidad de Vigo

\author{
M. Teresa Anguera Argilaga
}

Facultad de Psicología

Universidad de Barcelona

\begin{abstract}
This paper studies the process of interaction among the members of a soccer team using observational methodology. Data were collected from six matches played by Deportivo La Coruña during the 2000-01 season, using the polar coordinates technique to establish the activation or inhibition relationships among team members. This analysis allows the reduction of data from the value Zsum, introduced by Cochran [1] and applied by Sackett [1]. Polar coordinates analysis allows the combination of diachronic and synchronic perspectives through the representation of the values obtained as vector modules and angles (polar coordinates). The nature of the interactive relationship, depending on the quadrant in which it is located is represented by the angle, while the degree of significance depends on the vector module ( $>1.96$ at a level of significance of $5 \%$ ).
\end{abstract}

Key Words: Players' interactions, polar coordinates technique, activation and inhibition relationships, game analysis, professional soccer

\author{
RESUMO \\ Utilização da técnica de coordenadas polares para estudar a inte- \\ raç̧ẫo em jogadores profissionais de futebol
}

Neste trabalho centrámo-nos no estudo do processo de interacção que se estabelece entre os membros de uma equipa de futebol. Para levar a cabo o estudo foi utilizada a metodologia observacional, a partir do visionamento de seis jogos disputados pelo Real Club Deportivo de A Coruña durante a temporada de 2000-01. A análise dos dados foi realizada a partir da técnica de coordenadas polares, a qual permite estabelecer as diferentes relações de activação ou inibição que se processam entre as categorias que integram o instrumento de registo e codificação. Esta análise permite levar a cabo uma redução dos dados a partir da estatística Zsum, proposta por Cochran (8) e aplicada por Sackett (13). A análise das coordenadas polares permite uma leitura conjugada das perspectivas diacrónica e sincrónica do comportamento dos jogadores, mediante a representação dos valores obtidos sob a forma de módulos e ângulos de vectores (coordenadas polares). O módulo do vector $(>1,96)$ representa o significado; $e$ o ângulo, dependendo do quadrante em que se encontre, traduz a natureza da relação interactiva.

Palavras-chave: Interacções de jogadores, técnica de coordenadas polares, relações de activação e de inibição, observação em futebol, desporto de rendimento. 


\section{INTRODUCTION}

Unlike other psychomotor activities and sports, the action in soccer is built up collectively. With time, the play becomes increasingly complex, through the progressive complication of the structure of motor interpersonal relations - defined as the system $N+1$ intervening in the action - and through the difficulty of carrying out required behaviours [2]. Players' involvement is not limited to their immediate surroundings; it can depend on events which take place in another area of the field and do not directly involve them, but have an influence on what occurs in their vicinity.

This particular feature makes it difficult to understand the behaviour of competitive sportsmen, for two reasons. First, players' conduct cannot be readily explained by their personal attributes. When their behaviour or the choices they make depend on the behaviour or choices of others, it is not usually possible to obtain small sets of individuals merely by addition or extrapolation. Second, the composition of individual actions produces the so-called aggregate effects and can prompt perverse effects in the behaviour of sportsmen.

These two problems mean that sportsmen's behaviour appears to the observer as indeterminate (the complexity from the observer's point of view). This makes it difficult to direct research lines in particular areas of activity in team games [1] and also restricts our ability to establish a correlation and/or consistency between the internal logic of the game and the course that intervention should take in training sessions [1]. How can this situation be overcome? In our view, the core of the problem for researchers trying to understand the behaviour of sportsmen lies in uncovering the complex relations that link the subjective intentions of each individual in the various stages of the game to the opportunities and limitations imposed by the social context in which they are involved.

However, the proposal that the context in soccer entails participation in different dimensions or levels of interaction is valid only when these levels can be identified and empirically verified. This is the purpose of the present study.

Building on earlier work $[3,4]$ that suggested the existence of stable interactions among players in the same team, we will try to identify the dyadic groupings that link sportsmen to each other in order to reveal the various dimensions that make up the action in soccer: from the micro level of the behaviour of individual players to the macro level of the behaviour of teams.

\section{POLAR COORDINATES ANALYSIS. REASONS FOR OUR CHOICE OF METHODOLOGY.}

Polar coordinates analysis, first described by [5], is a double data reduction strategy which provides a vector representation of the complex network of interrelations among the different categories (or configurations of field formats) that make up an ad hoc system produced to record the behavioural flow deriving from any activity or situation.

The structure of the polar coordinates technique is based on the complementarity of two analytical perspectives $[6,7]$ :

1. Prospective perspective: A criterion behaviour is established for each analysis. This behaviour is proposed as the trigger of a series of connections with the rest of the categories, known as matching behaviours. In this paper the criterion behaviour was the participation in play of each player.

The first part of the process follows the same operations as the simple lag technique for sequential analysis [5, 8-10]. Starting from a number $r$ of lags specified in each case, the tables of matching frequencies and matching probabilities (expected and observed) are produced and the corresponding $\boldsymbol{Z}$ statistics are calculated. This provides us with a matrix, $k \times r$, where $k$ is the number of categories in the system (or the number of field format configurations), and $r$ the number of lags taken into account. Thus far only the prospective perspective has been considered, that is to say the result of considering the forward evolution of the flow of social exchanges and of the individual with the environment.

2. Retrospective perspective: This perspective aims to establish the extent to which previous events in the behavioural flow demonstrate a significant intensity in the connection of each of the $k$ categories in the system to the focal behaviour, which in this retrospective perspective takes the role of the matching behaviour. 
That is, we want to know whether the association between each of the categories of the system or field format configurations (now regarded as the criterion behaviour) is either excitatory or inhibitory (that is, statistically significant or non-significant) with respect to the focal behaviour which is now in the role of the matching behaviour.

Anguera [11] suggested that there may be a genuine retrospectivity through the criterion behaviour and "backwards", considering negative lags, and detecting the consistency of actions of order $n$ previous to the criterion behaviour. If $\mathrm{E}$ is the criterion behaviour, then $\mathrm{A}, \mathrm{B}, \mathrm{C}$ and $\mathrm{D}$ would be matching behaviours, but only considering negative lags (Figure 1). In agreement with this suggestion, behavioural patterns obtained through retrospective sequential analysis provide us with a mirror image of how the last, last but one etc., behaviours previous to the criterion behaviour maintain a stable relationship with the others, and consequently the actions that are "preparatory" to the event of the criterion behaviour, bearing in mind that each behavioural pattern is composed exclusively by the codes (category codes or field format configuration codes) that were shown to be excitatory or significant in each of the negative lags considered.

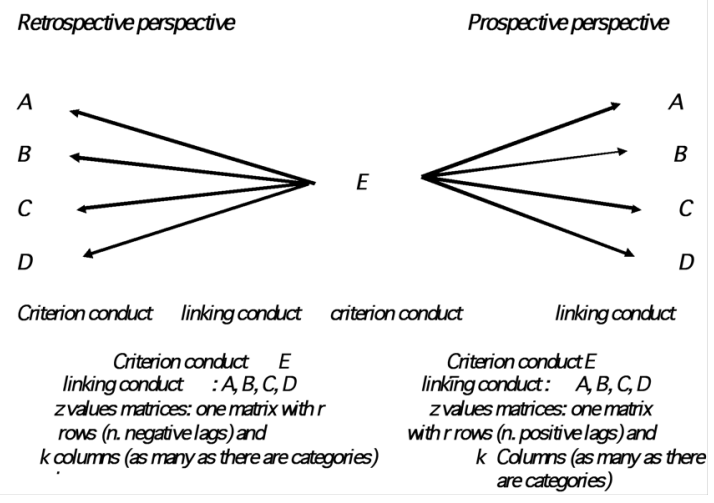

Figure 1. Polar coordinates analysis: Modified outline of genuine retrospectivity.
With the $z$ values of relative indexes of sequential dependence [12], we can apply an extremely powerful technique for the reduction of data by calculating the Zsum statistic described by [13], consisting in : that is, for each of the columns corresponding to each of the $\mathbf{z}$ value matrices - which are independent of one another - the sum of those values divided by the square root of the number of lags considered throughout the process.

The Zsum statistic is based on the principle that the sum of a number $r$ (since there as many as there are lags) of independent $z$ scores follows a normal distribution, with $\mathrm{m}=0$ and $\mathrm{s}=1$. Consequently, we obtain as many Zsum as there are categories in each of the perspective, the prospective and the retrospective; the ones corresponding to the former are termed criterion Zsum and the latter matching Zsum. Each Zsum can be either positive or negative, and so the set of signs will determine in which of the four possible quadrants the categories will fall in relation to the focal behaviour adopted (Figure 2).

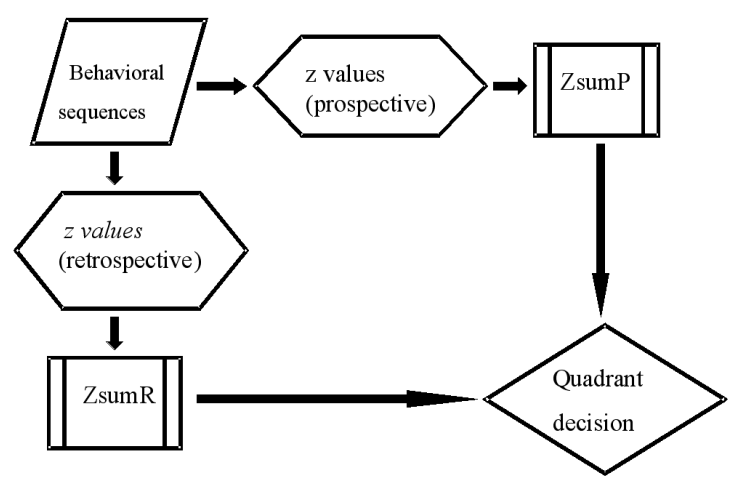

Figure 2. Polar coordinates analysis: Process (Anguera, 2001].

Each quadrant is characterised as follows (Figure 3):

Quadrant I $(++)$. Mutually excitatory criterion and matching behaviours.

Quadrant II (- +). Inhibitory criterion behaviour and excitatory matching behaviour.

Quadrant III (- -). Mutually inhibitory criterion and matching behaviours.

Quadrant IV (+-). Excitatory criterion behaviour and inhibitory matching behaviour. 


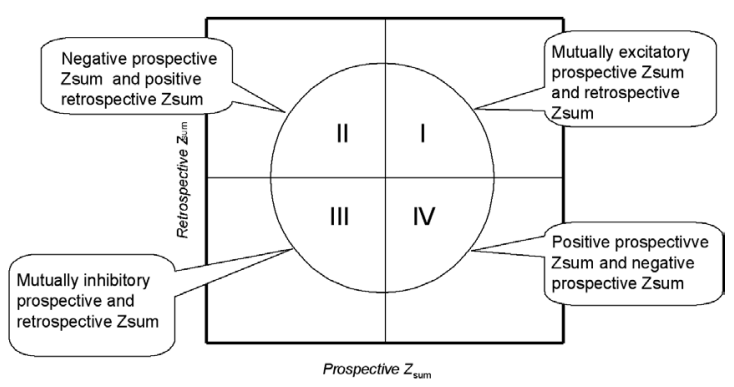

Figure 3. Polar coordinates analysis: decision on the quadrant for the Zsum.

The most genuine and useful representation provided by this data reduction technique is the one known as polar coordinates - after which the analysis technique is named. It is produced in vector form (with a module or length, and with a specified angle). Because categories are in different quadrants depending on the type of relation between the criterion behaviour and the matching behaviour, it is possible to determine the distance from the origin $(0,0)$ of the Zsum coordinates and the point of intersection (determined by the criterion Zsum value on the horizontal axis and the matching Zsum value on the vertical axis), which is the value of the radius or module (which, when $>1.96$, is statistically significant at a level of $5 \%$ ), and which is calculated by adding together the square root of the prospective Zsum and the square of the retrospective Zsum; the angle is calculated as the retrospective Zsum arc sine divided by the radius.

The quadrant in which each category is found should be borne in mind in order to calculate the value of this angle (Figure 4):

Quadrant I $(0<\varphi<90)=\varphi$

Quadrant II $(90<\varphi<180)=180-\varphi$

Quadrant III $(180<\varphi<270)=180+\varphi$

Quadrant IV $\left(270^{\circ}<\varphi<360^{\circ}\right)=360^{\circ}-\varphi$

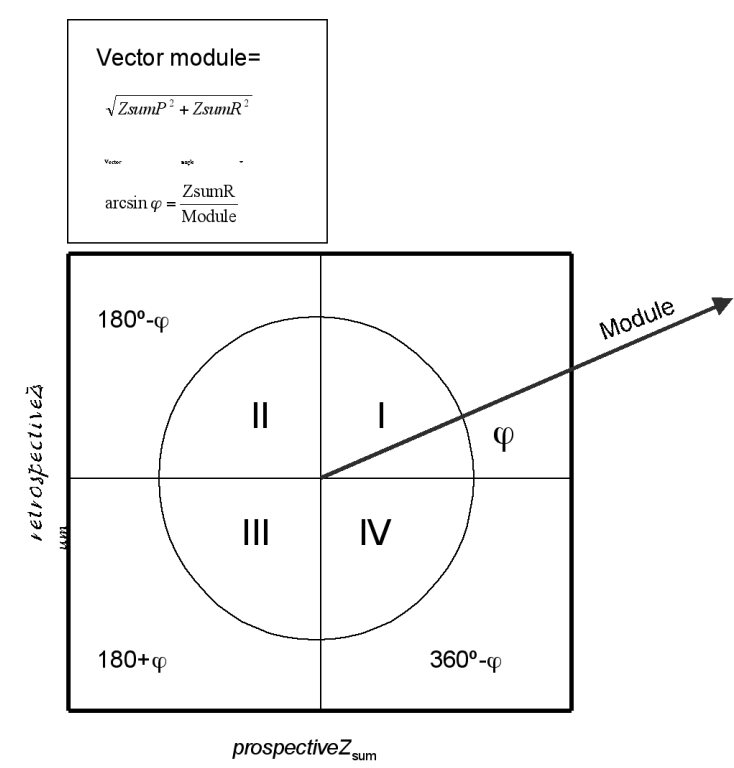

Figure 4. Vector module and angle.

So we can trace all the vectors corresponding to each of the codes depending on the focal behaviour considered, and every category or field format configuration can be considered as a focal behaviour when necessary for the evaluation. The technique is thus a powerful tool for overcoming the numerous methodological obstacles that face the attempt to identify all the interrelations among all the category codes or field format configurations.

\section{OBJECTIVES}

The study aims to produce an inter-relational map identifying stable dyadic groupings among a particular player and his team-mates during attacking play; that is, patterns of collective behaviour taking into account only the behaviours generated by the players in relation to the ball. At this point we should make two important definitions:

a) A team is attacking when it has possession of the ball.

b) A team has possession when one of its players has technical and tactical control over the ball and is able to continue the attacking process. 
All his actions and those of his team-mates are considered as components of the attacking sequence and therefore part of the attacking process.

\section{METHODOLOGY}

\section{Sample}

The study was conducted in a total of six soccer matches involving Deportivo La Coruña during the National League Championship and the Champions' League in the 2000-01 season. There was a number of reasons for the choice of the team and of the matches for analysis. First, Deportivo La Coruña was an ideal example of a high standard soccer team, since they had won the National League Championship the previous season (1999-2000). Second, the matches were chosen on the grounds that the team selection was the same or only slightly different in all of them; in addition, this line-up provided the team's best results during the season. The matches coded were:
- Deportivo - Oviedo.

National League Championship.

- Deportivo - Valencia.

National League Championship.

- Deportivo - Real Madrid.

National League Championship.

- Deportivo - Espanyol.

National League Championship.

- Deportivo - Paris Saint Germain. Champions League.

- Milan - Deportivo.

Champions League.

\section{Tool}

The ad hoc tool was a field format built up on the basis of the following criteria: Number of Player in Possession (PP), Sub-role of start of the attacking process, Spatial location on the field, Sub-role of build-up and development of the attacking process, Sub-role of end of the attacking process. Table 1 presents an outline of the field format.

Table 1. Field format in the attacking phase in soccer.

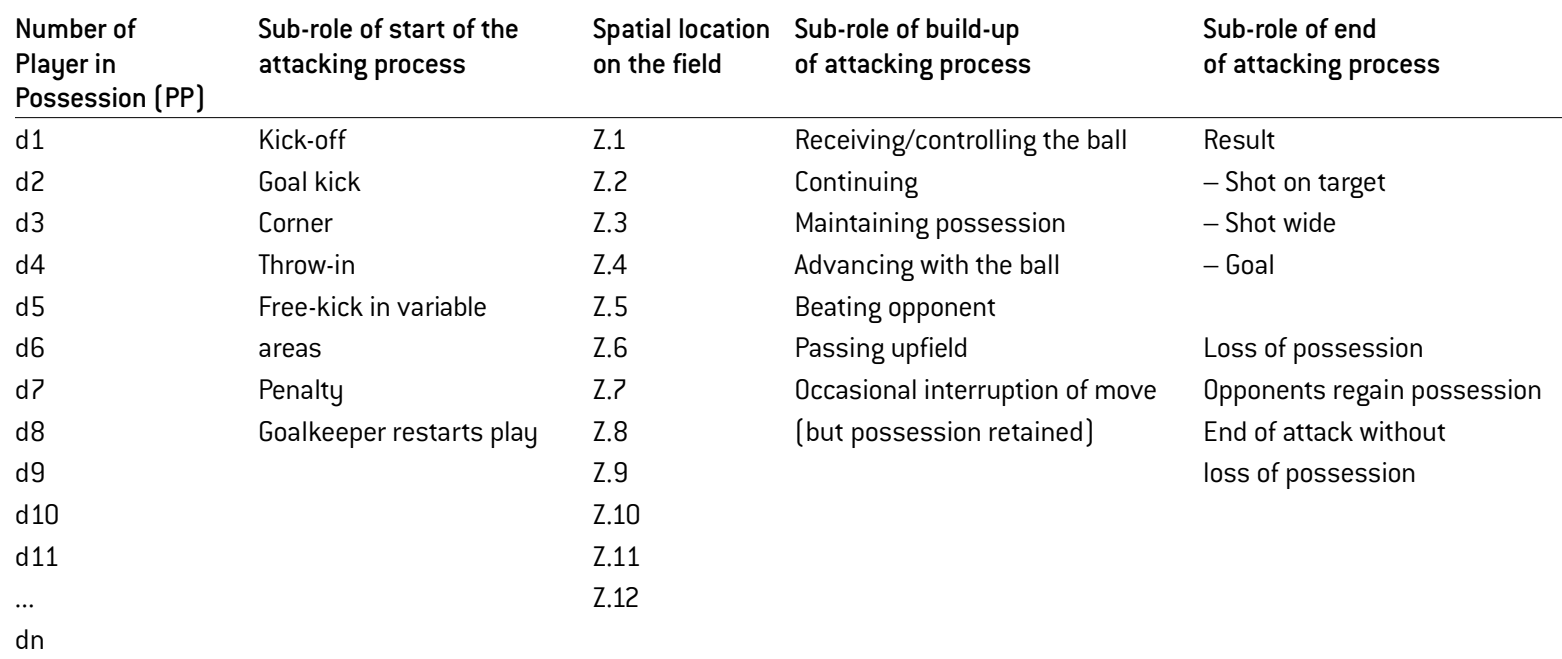

\section{Procedure}

The analysis was made from VHS videotapes of the games recorded from a state TV channel. The tapes focused on the spatial development of the game,

continually following the player in possession and his actions. The images were obtained using three different cameras: one provided a side-view, and the other two were placed behind each of the goals. 
The methodology used was systematised unobtrusive observation in a natural environment. To identify behaviour patterns for each attacking action, the following descriptive criteria were recorded: Number of Player in Possession (PP), Sub-role of start of the attacking process, Spatial location on the field, Sub-role of build-up and development of the attacking process, Sub-role of end of the attacking process.

For the sequential analysis prior to the calculation of the Zsum statistic we used the computer programme SDIS-GSEQ 4.0 devised by [9]. The data were coded as multi-events.

The observations and recordings were carried out by a team of five specially trained researchers, among them one of the authors of this study.

The data were controlled quantitatively and qualitatively. Each game was watched and coded twice.

Consensus agreement was used to obtain the qualitative profile, and the quantitative profile was obtained using a statistic measuring the degree of association. The coefficient used, Cohen's Kappa, takes into account random effects; it was above $90 \%$ in all games.

\section{RESULTS AND DISCUSSION}

To produce behaviour maps reflecting the motor interactions among the Deportivo players, represented on the polar coordinates diagram, the six games in the sample were coded. A total of 1192 clearly defined attacking actions were recorded to analyse the behavioural patterns. For each the following variables were specified:

- Number of Player in Possession (PP),

- Sub-role of start of the attacking process,

- Spatial location in the field,

- Sub-role of build-up and development of the attacking process,

- Sub-role of end of the attacking process.

We now present the behaviour maps in the polar coordinates graph, together with the tables for prospective and retrospective Zsum values, the quadrant of the vector, radius length, $y / z$ ratio, initial angle and transformed vector angle in the behaviour maps. In the graphic representation of the vector module the radius was 1.96, shown to scale. Each player in turn was designated as focal behaviour and his activity assessed in relation to the rest of members in the team.

We wanted to determine the relation of activation and inhibition among the players' behaviours, and to compare the results obtained for the relations among them from both prospective and retrospective perspectives. The figures and tables below present these relations clearly. 
Table 2. Module and angle of the vectors corresponding to the interrelations among the focal category player (No 2) and the rest of the players.

Combination of the prospective and retrospective perspectives, with No 2 as focal behaviour

\begin{tabular}{|c|c|c|c|c|c|c|c|}
\hline Player & $\begin{array}{c}\text { Prospective } \\
\text { [Criterion Zsum ] x }\end{array}$ & $\begin{array}{c}\text { Retrospective } \\
\text { (Matching Zsum) y }\end{array}$ & Quadrant & $\begin{array}{l}\text { Radius } \\
\sqrt{x^{2}+y^{2}}\end{array}$ & $\frac{y}{\text { radius }}$ & Angle $\varphi$ & $\begin{array}{c}\text { Transformed } \\
\text { angle }\end{array}$ \\
\hline No 3 & -9.46 & -8.60 & III & 12.79 & 0.67 & 42.1 & 222.1 \\
\hline No 4 & 0 & 1.14 & & & & & \\
\hline No 6 & -1.15 & 6.59 & II & 6.69 & 0.99 & 81.9 & 98.1 \\
\hline No? & 7.17 & -9.17 & IV & 11.64 & 0.79 & 52.2 & 307.8 \\
\hline No 8 & 1.43 & 4.01 & I & 4.26 & 0.94 & 70 & 70 \\
\hline No 10 & -4.30 & -7.17 & III & 8.36 & 0.86 & 61.6 & 241.6 \\
\hline No 13 & -3.15 & 0.57 & $\|$ & 3.20 & 0.18 & 10.4 & 169.6 \\
\hline No 14 & 2.58 & 6.31 & 1 & 6.81 & 0.93 & 68.4 & 68.4 \\
\hline No 18 & 8.60 & -2.87 & IV & 9.07 & 0.32 & 18.7 & 341.3 \\
\hline No 20 & -1.72 & 8.03 & $\|$ & 8.21 & 0.98 & 78.5 & 101.5 \\
\hline
\end{tabular}

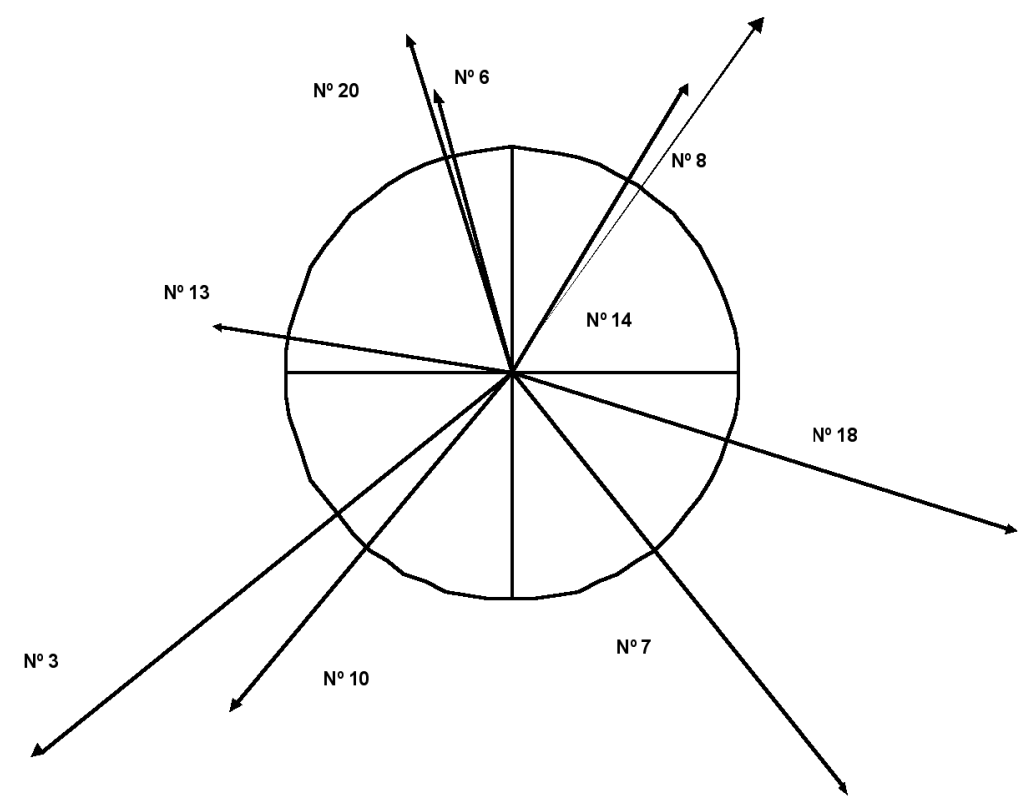

Figure 5. Vector representation of the interrelations among the focal category player ( No 2) and the rest of the players. 
Table 3. Module and angle of the vectors corresponding to the interrelations among the focal category player (No 3) and the rest of the players.

Combination of the prospective and retrospective perspectives, with No 3 as focal behaviour

\begin{tabular}{|c|c|c|c|c|c|c|c|}
\hline Player & $\begin{array}{c}\text { Prospective } \\
\text { [Criterion Zsum] x }\end{array}$ & $\begin{array}{c}\text { Retrospective } \\
\text { (Matching Zsum) y }\end{array}$ & Quadrant & $\begin{array}{l}\text { Radius } \\
\sqrt{x^{2}+y^{2}}\end{array}$ & $\frac{y}{\text { radius }}$ & Angle $\varphi$ & $\begin{array}{c}\text { Transformed } \\
\text { angle }\end{array}$ \\
\hline No 2 & -8.77 & -7.36 & III & 11.45 & 0.64 & 39.8 & 219.8 \\
\hline No 4 & 1.13 & 3.68 & I & 3.85 & 0.96 & 73.7 & 73.7 \\
\hline No 6 & 4.8 & 12.17 & I & 13.08 & 0.93 & 68.4 & 68.4 \\
\hline No? & 2.83 & -9.62 & IV & 10.03 & 0.96 & 73.7 & 286.3 \\
\hline No 8 & 3.96 & 3.96 & I & 5.60 & 0.71 & 45.2 & 45.2 \\
\hline No 10 & 16.41 & 4.53 & 1 & 17.02 & 0.27 & 15.7 & 15.7 \\
\hline No 13 & -1.99 & 1.67 & ॥ & 2.60 & 0.64 & 39.9 & 140.1 \\
\hline No 14 & -5.67 & -3.40 & III & 6.61 & 0.51 & 30.7 & 210.7 \\
\hline No 18 & -5.37 & -7.10 & III & 8.90 & 0.80 & 53.1 & 230.1 \\
\hline No 20 & -5.09 & -4.53 & III & 6.81 & 0.67 & 42.1 & 222.1 \\
\hline
\end{tabular}

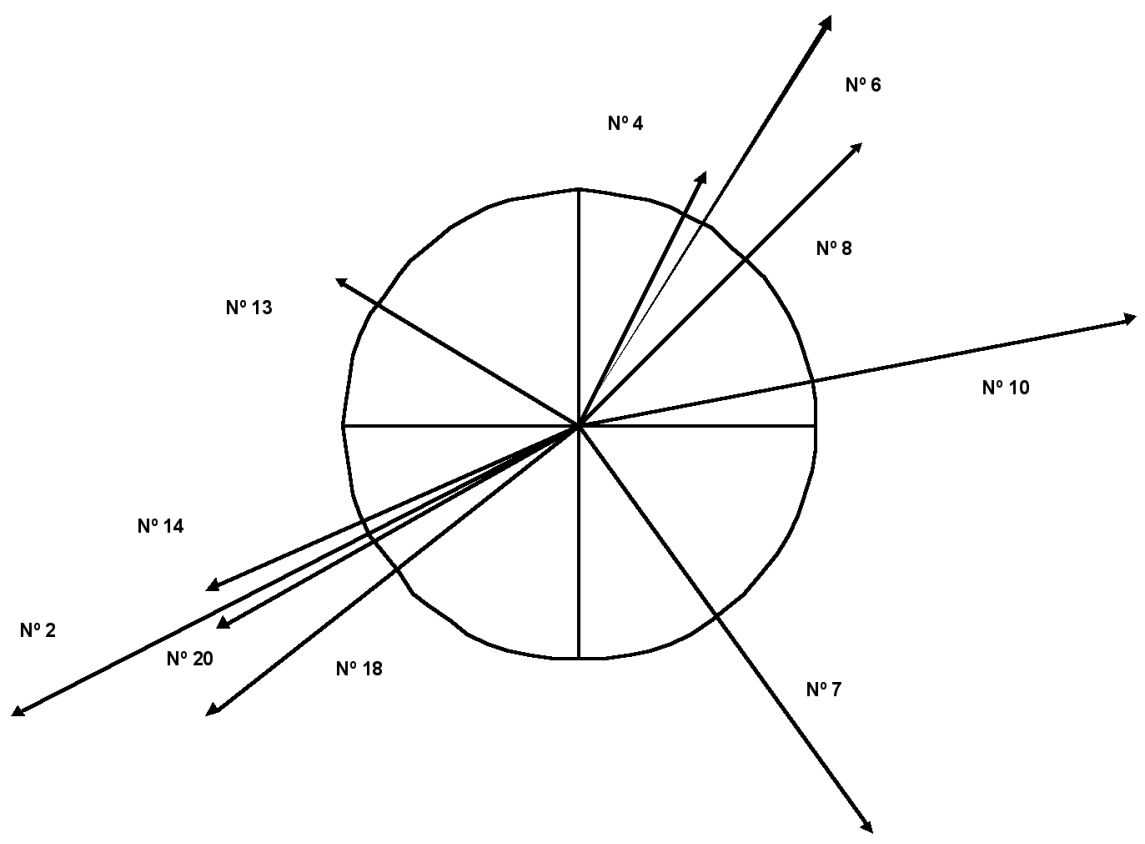

Figure 6. Vector representation of the interrelations among the focal category player (No 3) and the rest of the players. 
Table 4. Module and angle of the vectors corresponding to the interrelations among the focal category player (No 4) and the rest of the players.

Combination of the prospective and retrospective perspectives, with No 4 as focal behaviour

\begin{tabular}{|c|c|c|c|c|c|c|c|}
\hline Player & $\begin{array}{c}\text { Prospective } \\
\text { [Criterion Zsum] x }\end{array}$ & $\begin{array}{c}\text { Retrospective } \\
\text { [Matching Zsum] y }\end{array}$ & Quadrant & $\begin{array}{l}\text { Radius } \\
\sqrt{x^{2}+y^{2}}\end{array}$ & $\frac{y}{\text { radius }}$ & Angle $\varphi$ & $\begin{array}{c}\text { Transformed } \\
\text { angle }\end{array}$ \\
\hline No 2 & -4.32 & 5.19 & IV & 6.75 & 0.77 & 50.4 & 309.6 \\
\hline No 3 & 5.19 & 5.19 & I & 7.40 & 0.71 & 45.2 & 45.2 \\
\hline No 6 & 4.91 & 0 & & & & & \\
\hline No? & -4.91 & -11.54 & III & 12.54 & 0.92 & 66.9 & 246.9 \\
\hline No 8 & 1.15 & -5.77 & 1 & 5.88 & 0.98 & 78.5 & 78.5 \\
\hline No 10 & 6.35 & -6.35 & IV & 8.98 & 0.71 & 45.2 & 314.8 \\
\hline No 13 & 0.60 & 6.64 & I & 6.67 & 1 & 90 & 90 \\
\hline No 14 & -4.04 & -3.17 & III & 5.14 & 0.62 & 38.3 & 218.3 \\
\hline No 18 & -5.19 & -7.79 & III & 9.36 & 0.83 & 56.1 & 236.1 \\
\hline No 20 & 3.46 & 8.37 & I & 9.06 & 0.92 & 66.9 & 66.9 \\
\hline
\end{tabular}

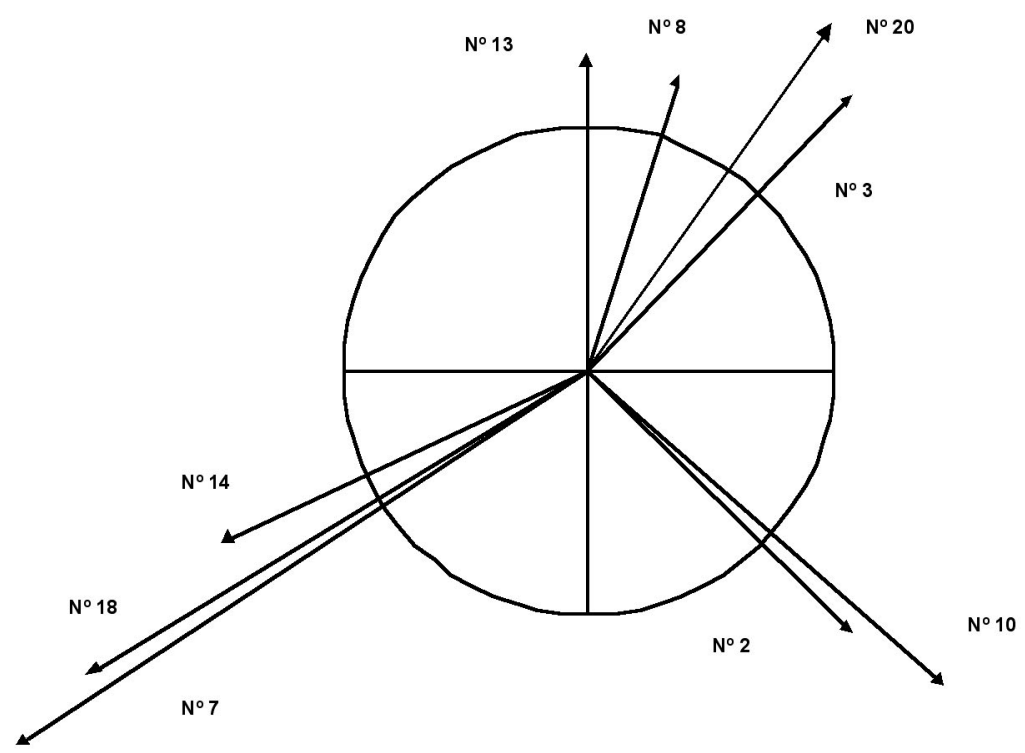

Figure 7. Vector representation of the interrelations among the focal category player (No 4) and the rest of the players. 
Table 5. Module and angle of the vectors corresponding to the interrelations among the focal category player (No 6) and the rest of the players

Combination of the prospective and retrospective perspectives, with No 6 as focal behaviour

\begin{tabular}{|c|c|c|c|c|c|c|c|}
\hline Player & $\begin{array}{c}\text { Prospective } \\
\text { (Criterion Zsum) } x\end{array}$ & $\begin{array}{c}\text { Retrospective } \\
\text { (Matching Zsum) y }\end{array}$ & Quadrant & $\begin{array}{l}\text { Radius } \\
\sqrt{x^{2}+y^{2}}\end{array}$ & $\frac{y}{\text { radius }}$ & Angle $\varphi$ & $\begin{array}{c}\text { Transformed } \\
\text { angle }\end{array}$ \\
\hline No 2 & 0.28 & 1.43 & 1 & 1.46 & 0.98 & 78.5 & 78.5 \\
\hline No 3 & 7.16 & 3.85 & I & 8.13 & 0.47 & 28 & 28 \\
\hline No 4 & 1.71 & 6.88 & I & 7.10 & 0.97 & 75.9 & 75.9 \\
\hline No? & -5.16 & -10.88 & III & 12.05 & 0.90 & 64.2 & 244.2 \\
\hline No 8 & 6.02 & -4.31 & IV & 7.40 & 0.58 & 35.5 & 324.5 \\
\hline No 10 & 4.86 & 2.87 & I & 5.64 & 0.51 & 30.7 & 30.7 \\
\hline No 13 & -3.72 & -0.57 & III & 3.76 & 0.15 & 8.6 & 188.6 \\
\hline No 14 & 0.85 & 1.72 & I & 1.92 & 0.90 & 64.2 & 64.2 \\
\hline No 18 & 0.84 & -8.30 & IV & 8.34 & 1 & 90 & 90 \\
\hline No 20 & -2.58 & 0.51 & $\|$ & 2.63 & 0.19 & 11 & 169 \\
\hline
\end{tabular}

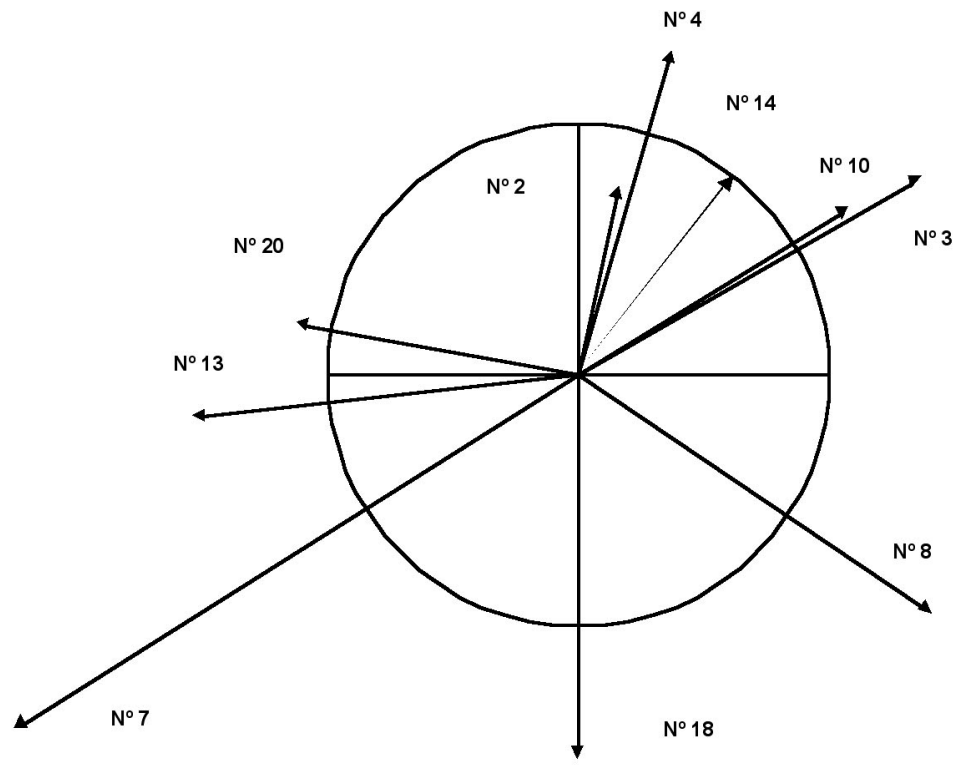

Figure 8. Vector representation of the interrelations among the focal category player (No 6) and the rest of the players. 
Table 6. Module and angle of the vectors corresponding to the interrelations among the focal category player (No ?) and the rest of the players.

Combination of the prospective and retrospective perspectives, with No 7 as focal behaviour

\begin{tabular}{lcccccccc}
\hline Player & $\begin{array}{c}\text { Prospective } \\
\text { (Criterion Zsum) } \mathbf{x}\end{array}$ & $\begin{array}{c}\text { Retrospective } \\
\text { (Matching Zsum) } \mathbf{y}\end{array}$ & Quadrant & $\begin{array}{c}\text { Radius } \\
\sqrt{x^{2}+y^{2}}\end{array}$ & $\begin{array}{c}y \\
\text { radius }\end{array}$ & $\begin{array}{c}\text { Angle } \varphi \\
\text { Transformed } \\
\text { angle }\end{array}$ \\
\hline No 2 & -2.51 & 5.87 & II & 6.39 & 0.92 & 66.9 & 113.1 \\
No 3 & -6.15 & 4.48 & II & 7.60 & 0.59 & 36.2 & 143.8 \\
No 4 & -2.80 & -2.24 & III & 3.59 & 0.62 & 38.3 & 218.3 \\
No 6 & -4.47 & -3.07 & III & 5.42 & 0.57 & 34.8 & 214.8 \\
No 8 & 8.67 & 4.19 & I & 9.63 & 0.43 & 25.5 & 25.5 \\
No 10 & 7.26 & 1.40 & I & 7.40 & 0.19 & 11 & 11 \\
No 13 & -3.64 & 1.12 & II & 3.81 & 0.30 & 17.5 & 162.5 \\
No 14 & -1.88 & 2.24 & II & 2.92 & 0.77 & 50.4 & 129.6 \\
No 18 & 10.34 & 0.56 & I & 10.40 & 0.05 & 2.9 & 2.9 \\
No 20 & -7.83 & -1.68 & III & 8.01 & 0.21 & 12.1 & 192.2
\end{tabular}

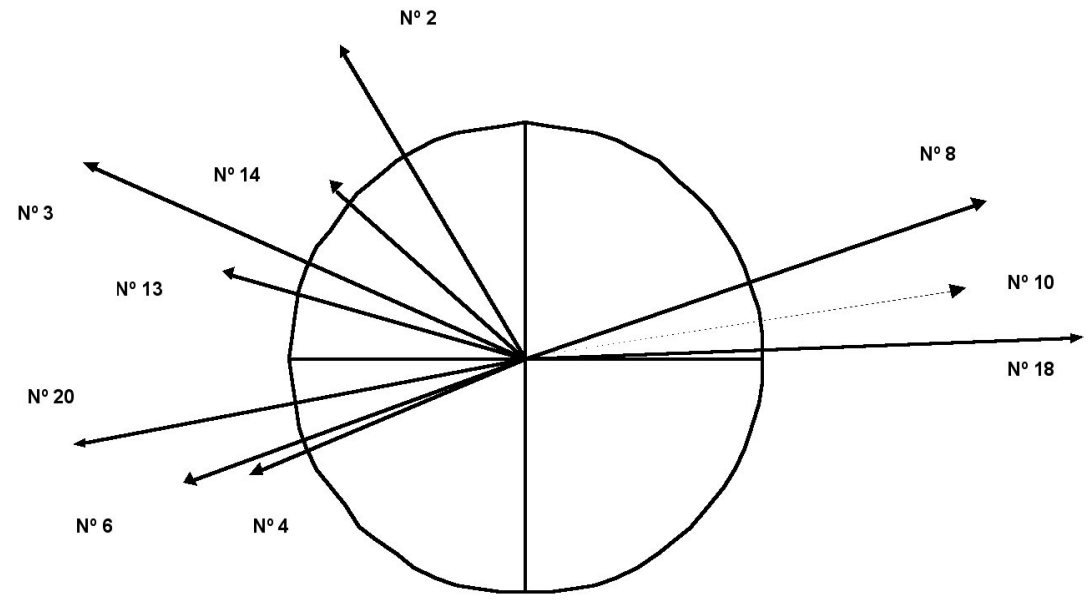

Figure 9. Vector representation of the interrelations among the focal category player (No 7) and the rest of the players. 
Table 7. Module and angle of the vectors corresponding to the interrelations among the focal category player (No 8) and the rest of the players.

Combination of the prospective and retrospective perspectives, with No 8 as focal behaviour

\begin{tabular}{|c|c|c|c|c|c|c|c|}
\hline Player & $\begin{array}{c}\text { Prospective } \\
\text { [Criterion Zsum] x }\end{array}$ & $\begin{array}{c}\text { Retrospective } \\
\text { (Matching Zsum) y }\end{array}$ & Quadrant & $\begin{array}{l}\text { Radius } \\
\sqrt{x^{2}+y^{2}}\end{array}$ & $\frac{y}{\text { radius }}$ & Angle $\varphi$ & $\begin{array}{c}\text { Transformed } \\
\text { angle }\end{array}$ \\
\hline No 2 & 2.33 & 3.51 & 1 & 4.21 & 0.83 & 56.1 & 56.1 \\
\hline No 3 & 2.63 & 4.96 & I & 5.61 & 0.88 & 61.6 & 61.6 \\
\hline No 4 & 1.45 & 1.46 & 1 & 2.06 & 0.71 & 45.2 & 45.2 \\
\hline No 6 & -1.75 & 7.90 & $\|$ & 8.10 & 0.98 & 78.5 & 101.5 \\
\hline No? & 11.68 & -5.55 & IV & 12.93 & 0.43 & 25.5 & 334.5 \\
\hline No 10 & 7.60 & 4.97 & I & 9.10 & 0.55 & 33.4 & 33.4 \\
\hline No 13 & -4.38 & -0.26 & III & 4.39 & 0.06 & 3.4 & 183.4 \\
\hline No 14 & 0.30 & 3.21 & 1 & 3.22 & 1 & 90 & 90 \\
\hline No 18 & 2.04 & -2.64 & IV & 3.37 & 0.80 & 53.1 & 306.9 \\
\hline No 20 & -6.13 & 0.29 & $\|$ & 6.14 & 0.05 & 2.9 & 177.1 \\
\hline
\end{tabular}

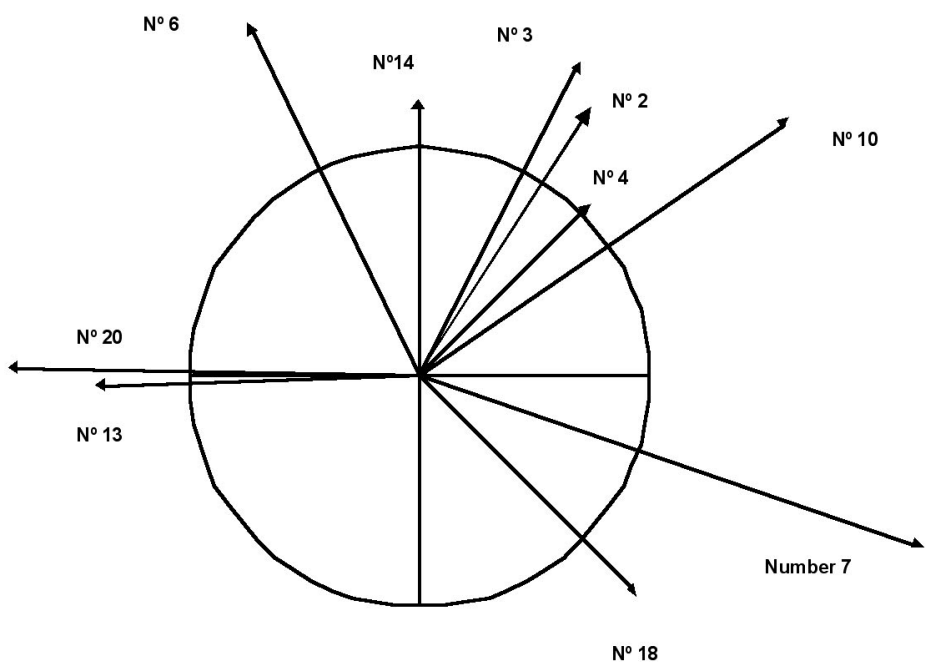

Figure 10. Vector representation of the interrelations among the focal category player (No 8) and the rest of the players. 
Table 8. Module and angle of the vectors corresponding to the interrelations among the focal category player (No 10) and the rest of the players.

Combination of the prospective and retrospective perspectives, with No 10 as focal behaviour

\begin{tabular}{lcccccccc}
\hline Player & $\begin{array}{c}\text { Prospective } \\
\text { (Criterion Zsum) } \mathbf{x}\end{array}$ & $\begin{array}{c}\text { Retrospective } \\
\text { (Matching Zsum) } \mathbf{y}\end{array}$ & Quadrant & $\begin{array}{c}\text { Radius } \\
\sqrt{x^{2}+y^{2}}\end{array}$ & $\begin{array}{c}y \\
\text { radius }\end{array}$ & $\begin{array}{c}\text { Angle } \varphi \\
\text { Transformed } \\
\text { angle }\end{array}$ \\
\hline No 2 & -5.70 & -3.70 & 16.52 & III & 6.80 & 0.55 & 33.4 & 213.4 \\
No 3 & 5.85 & 4.83 & I & 17.53 & 0.94 & 70.1 & 70.1 \\
No 4 & -2.27 & 5.98 & II & 5.34 & 0.91 & 65.5 & 114.5 \\
No 6 & 2.84 & -5.98 & I & 6.62 & 0.90 & 64.2 & 64.2 \\
No 7 & 8.54 & 5.70 & IV & 10.43 & 0.57 & 34.8 & 325.2 \\
No 8 & 10.82 & -1.42 & I & 12.23 & 0.47 & 28 & 28 \\
No 13 & -1.91 & 0.28 & I & 2.38 & 0.60 & 36.9 & 216.9 \\
No 14 & 1.42 & -7.40 & IV & 7.45 & 0.19 & 11 & 11 \\
No 18 & 0.85 & -3.13 & III & 8.45 & 0.99 & 81.9 & 278.1 \\
No 20 & -8.34 & & & & 0.35 & 20.5 & 200.5
\end{tabular}

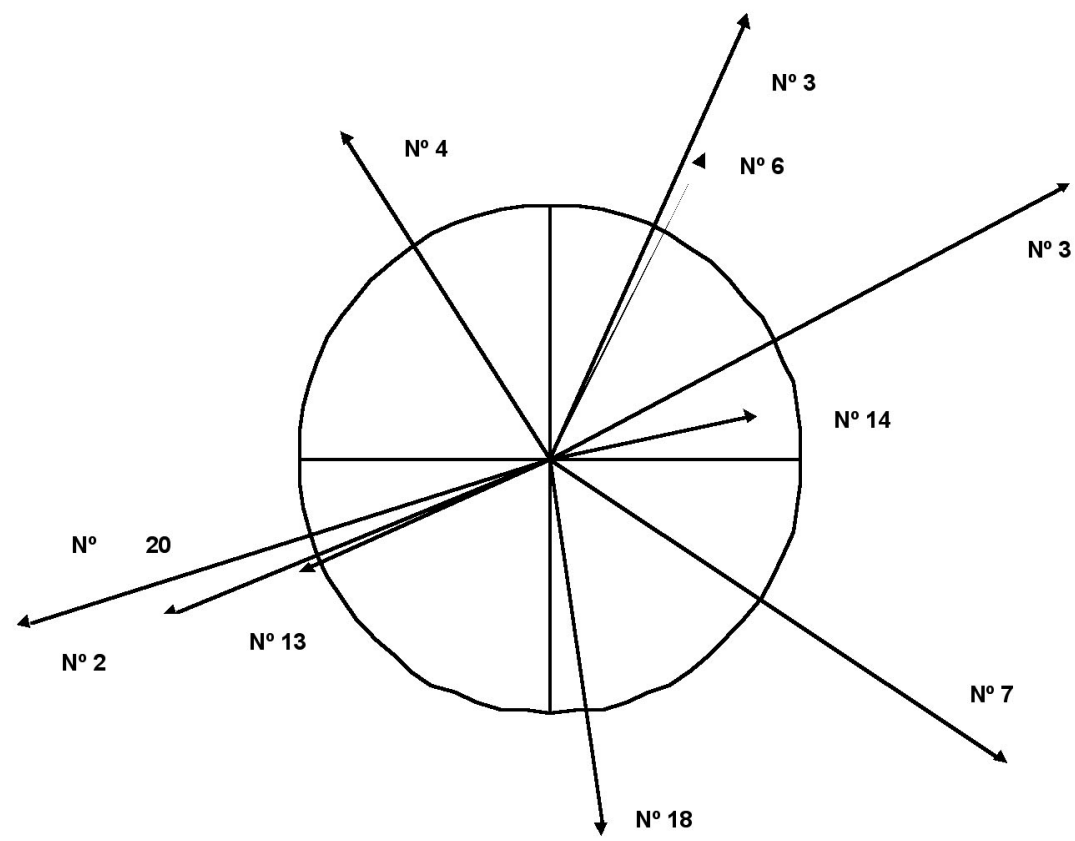

Figure 11. Vector representation of the interrelations among the focal category player (No 10) and the rest of the players. 
Table 9. Module and angle of the vectors corresponding to the interrelations among the focal category player (No 13) and the rest of the players.

Combination of the prospective and retrospective perspectives, with No 13 as focal behaviour

\begin{tabular}{|c|c|c|c|c|c|c|c|}
\hline Player & $\begin{array}{c}\text { Prospective } \\
\text { [Criterion Zsum] x }\end{array}$ & $\begin{array}{c}\text { Retrospective } \\
\text { (Matching Zsum) y }\end{array}$ & Quadrant & $\begin{array}{l}\text { Radius } \\
\sqrt{x^{2}+y^{2}}\end{array}$ & $\frac{y}{\text { radius }}$ & Angle $\varphi$ & $\begin{array}{c}\text { Transformed } \\
\text { angle }\end{array}$ \\
\hline No 2 & -2.20 & -0.82 & III & 2.35 & 0.35 & 20.5 & 200.5 \\
\hline No 3 & -9.60 & 14.78 & $\|$ & 17.62 & 0.84 & 57.1 & 122.9 \\
\hline No 4 & 7.12 & 19.75 & I & 21.00 & 0.94 & 70.1 & 70.1 \\
\hline No 6 & 1.37 & -5.49 & IV & 5.69 & 0.97 & 75.9 & 284.1 \\
\hline No $?$ & 5.48 & -12.63 & IV & 13.76 & 0.92 & 66.9 & 293.1 \\
\hline No 8 & -3.02 & -13.73 & III & 14.06 & 0.98 & 78.5 & 258.5 \\
\hline No 10 & -4.61 & -15.10 & III & 15.79 & 0.96 & 73.7 & 253.7 \\
\hline No 14 & 2.33 & 0.55 & 1 & 2.39 & 0.30 & 17.5 & 17.5 \\
\hline No 18 & -2.19 & -1.10 & III & 2.45 & 0.45 & 26.7 & 200.7 \\
\hline No 20 & 9.60 & 7.95 & I & 12.46 & 0.64 & 39.8 & 39.8 \\
\hline
\end{tabular}

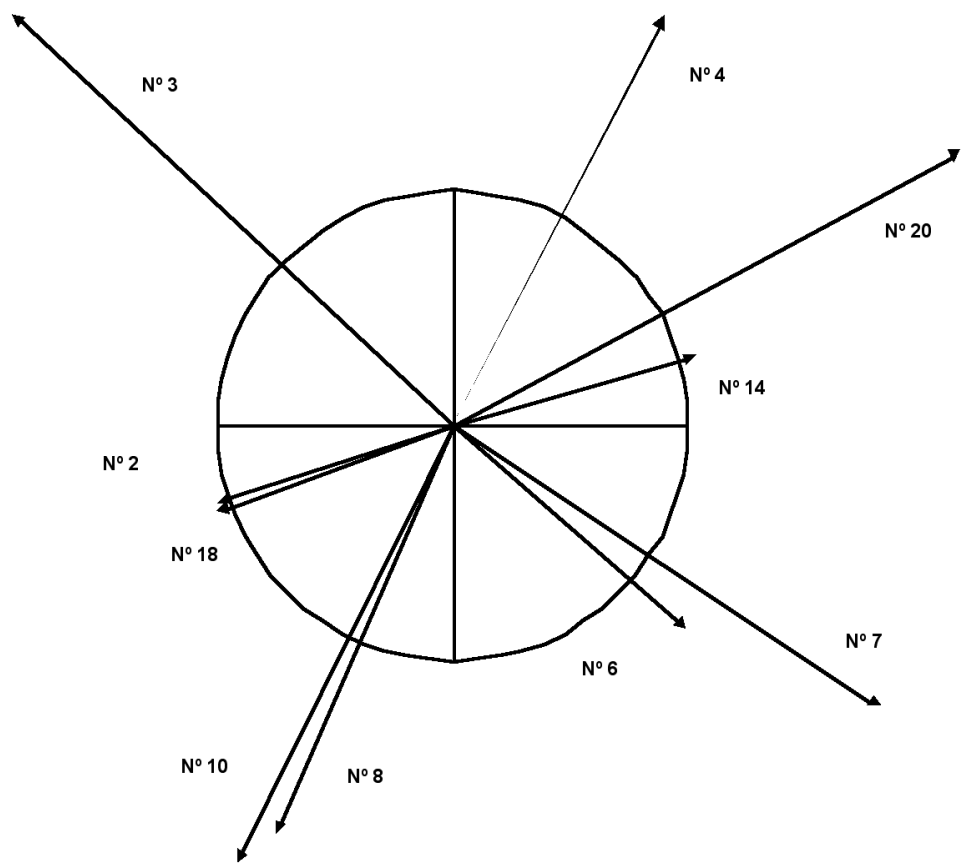

Figure 12. Vector representation of the interrelations among the focal category player (No 13) and the rest of the players. 
Table 10. Module and angle of the vectors corresponding to the interrelations among the focal category player (No 14) and the rest of the players.

Combination of the prospective and retrospective perspectives with No 14 as focal behaviour

\begin{tabular}{lcccccccc}
\hline Player & $\begin{array}{c}\text { Prospective } \\
\text { (Criterion Zsum) } \mathbf{x}\end{array}$ & $\begin{array}{c}\text { Retrospective } \\
\text { (Matching Zsum) } \mathbf{y}\end{array}$ & Quadrant & $\begin{array}{c}\text { Radius } \\
\sqrt{x^{2}+y^{2}}\end{array}$ & $\begin{array}{c}y \\
\text { radius }\end{array}$ & $\begin{array}{c}\text { Angle } \varphi \\
\text { Transformed } \\
\text { angle }\end{array}$ \\
\hline No 2 & 2.25 & 9.28 & I & 9.55 & 0.97 & 75.9 & 75.9 \\
No 3 & -3.93 & -6.75 & III & 7.81 & 0.86 & 59.3 & 239.3 \\
No 4 & -2.81 & -0.56 & III & 2.87 & 0.12 & 6.9 & 186.9 \\
No 6 & 0.84 & 8.44 & I & 8.49 & 1 & 90 & 90 \\
No 7 & 3.94 & -7.31 & IV & 8.30 & 0.88 & 61.6 & 298.4 \\
No 8 & 4.50 & -0.56 & IV & 4.53 & 0.12 & 6.9 & 353.1 \\
No 10 & 0.28 & 0.28 & I & 0.40 & 0.71 & 45.2 & 45.2 \\
No 13 & -3.35 & 0 & & & & & & \\
No 18 & 5.34 & -3.38 & IV & 6.31 & 0.53 & 32.0 & 328 \\
No 20 & -1.41 & 0.28 & II & 1.44 & 0.19 & 11 & 179
\end{tabular}

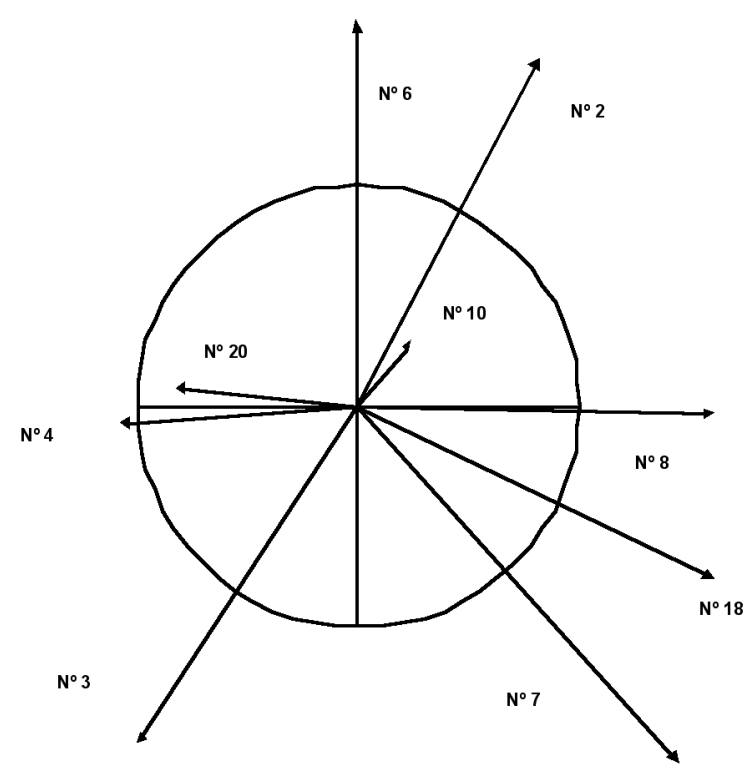

Figure 13. Vector representation of the interrelations among the focal category player (No 14) and the rest of the players. 
Table 11. Module and angle of the vectors corresponding to the interrelations among the focal category player (No 18) and the rest of the players

Combination of the prospective and retrospective perspectives with No18 as focal behaviour

\begin{tabular}{lccccccc}
\hline Player & $\begin{array}{c}\text { Prospective } \\
\text { (Criterion Zsum) } \mathbf{x}\end{array}$ & $\begin{array}{c}\text { Retrospective } \\
\text { (Matching Zsum) } \mathbf{y}\end{array}$ & Quadrant & $\begin{array}{c}\text { Radius } \\
\sqrt{x^{2}+y^{2}}\end{array}$ & $\begin{array}{c}y \\
\text { radius }\end{array}$ & $\begin{array}{c}\text { Angle } \varphi \\
\text { Transformed } \\
\text { angle }\end{array}$ \\
\hline No 2 & 2.22 & 11.67 & I & 11.88 & 0.98 & 78.5 & 78.5 \\
No 3 & -5.28 & -8.61 & III & 10.10 & 0.85 & 58.2 & 238.2 \\
No 4 & -3.73 & 1.66 & IV & 4.08 & 0.41 & 24.2 & 335.8 \\
No 6 & -5.83 & 6.37 & IV & 8.64 & 0.74 & 47.7 & 312.3 \\
No 7 & 17.22 & 0.55 & I & 17.23 & 0.03 & 1.7 & 1.7 \\
No 8 & 8.05 & 1.11 & I & 8.13 & 0.14 & 8.0 & 8.0 \\
No 10 & -4.16 & -3.60 & III & 5.50 & 0.65 & 40.5 & 220.5 \\
No 13 & -2.77 & -0.27 & III & 2.78 & 0.10 & 5.7 & 185.7 \\
No 14 & 2.5 & 5.83 & I & 6.34 & 0.92 & 66.9 & 66.9 \\
No 20 & -6.94 & 2.5 & II & 7.34 & 0.34 & 19.9 & 160.1
\end{tabular}

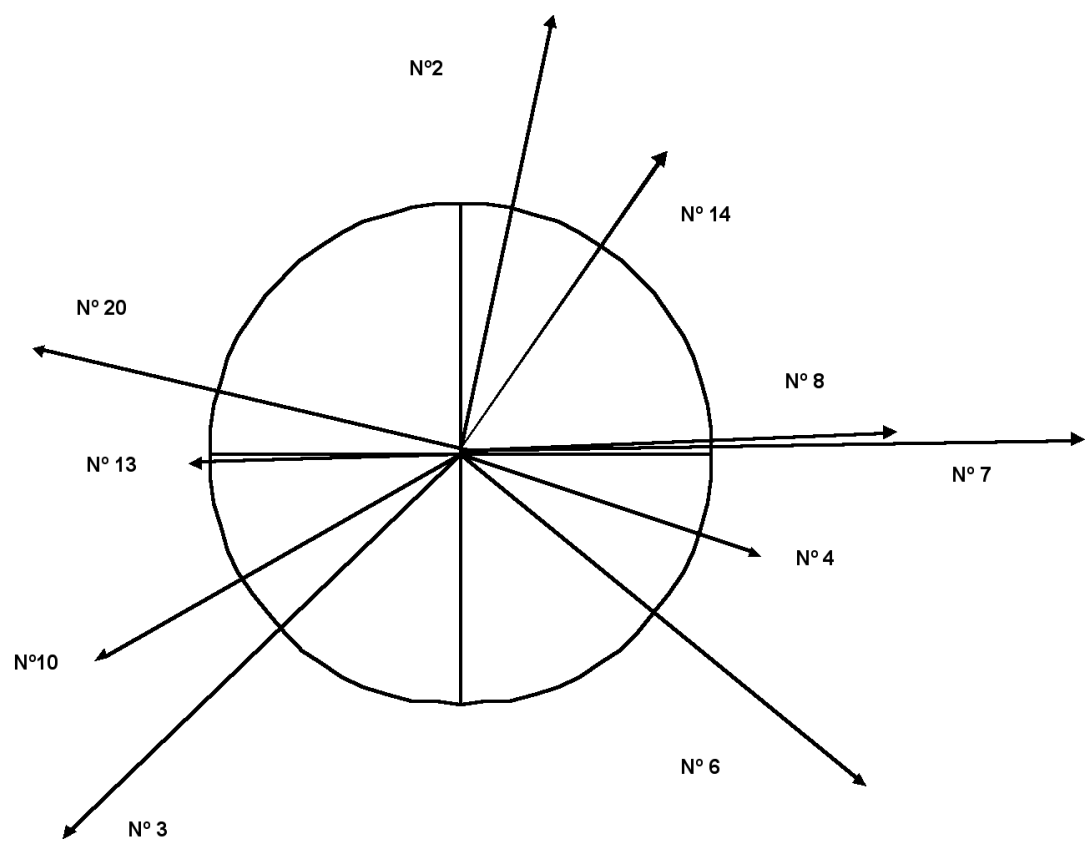

Figure 14. Vector representation of the interrelations among the focal category player (No 18) and the rest of the players. 
Table 12. Module and angle of the vectors corresponding to the interrelations among the focal category player (No 20) and the rest of the players.

Combination of the prospective and retrospective perspectives with No 20 as focal behaviour

\begin{tabular}{|c|c|c|c|c|c|c|c|}
\hline Player & $\begin{array}{c}\text { Prospective } \\
\text { [Criterion Zsum] } \mathbf{x}\end{array}$ & $\begin{array}{c}\text { Retrospective } \\
\text { [Matching Zsum) y }\end{array}$ & Quadrant & $\begin{array}{l}\text { Radius } \\
\sqrt{x^{2}+y^{2}}\end{array}$ & $\frac{y}{\text { radius }}$ & Angle $\varphi$ & $\begin{array}{c}\text { Transformed } \\
\text { angle }\end{array}$ \\
\hline No 2 & 4.36 & 6.54 & 1 & 7.86 & 0.83 & 56.1 & 56.1 \\
\hline No 3 & -2.18 & 0.82 & ॥ & 2.33 & 0.35 & 20.5 & 159.5 \\
\hline No 4 & 2.72 & 7.91 & I & 8.36 & 0.95 & 71.8 & 71.8 \\
\hline No 6 & 0.81 & 8.73 & 1 & 8.77 & 1 & 90 & 90 \\
\hline No $?$ & 5.36 & -10.36 & IV & 11.66 & 0.89 & 62.9 & 297.1 \\
\hline No 8 & 0.27 & -10.63 & IV & 10.63 & 1 & 90 & 90 \\
\hline No 10 & -1.36 & -8.18 & III & 8.30 & 0.99 & 81.9 & 260.9 \\
\hline No 13 & -1.76 & 6.55 & II & 6.78 & 0.97 & 75.9 & 104.1 \\
\hline No 14 & -1.36 & 1.36 & ॥ & 1.92 & 0.71 & 45.2 & 134.8 \\
\hline No 18 & 1.96 & -6.27 & IV & 6.57 & 0.95 & 71.8 & 288.2 \\
\hline
\end{tabular}

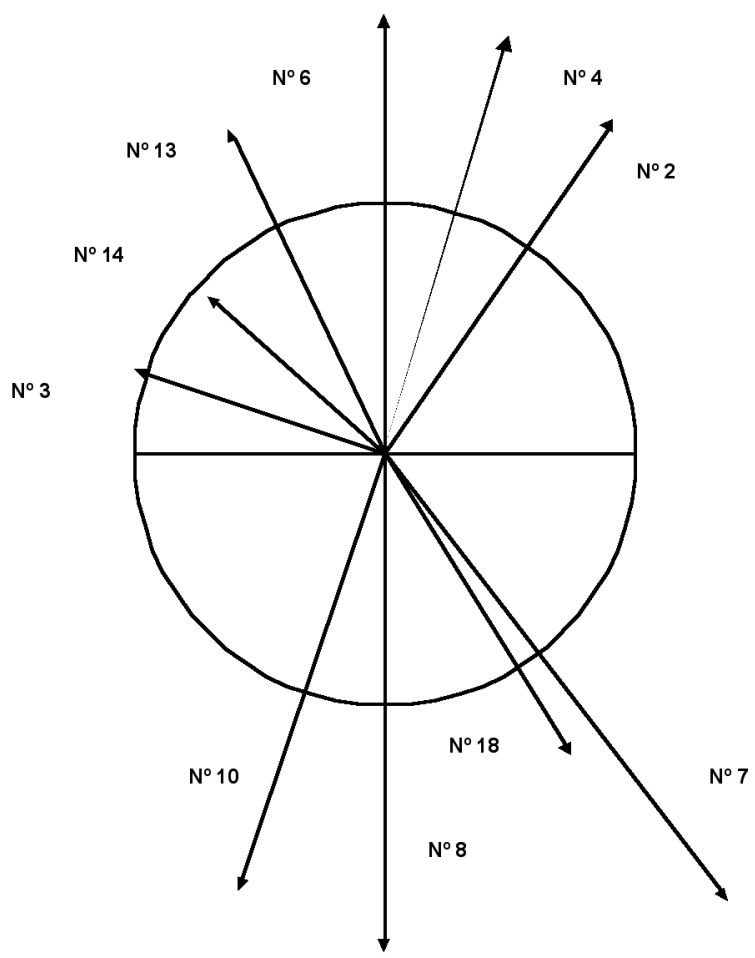

Figure 15. Vector representation of the interrelations among the focal category player (No 20) and the rest of the players. 
The results obtained provided empirical evidence of stable dyadic groupings among players of the same team in attacking play. The different sequences of association for each player suggest the existence of a selective network in the interactions among teammates. The results reveal the following statistically significant relations among players:

Table 13. Statistically significant relations among players.

\begin{tabular}{|c|c|c|}
\hline $\begin{array}{l}\text { Mutually excitatory } \\
\text { [Quadrant I] }\end{array}$ & $\begin{array}{l}\text { Asymmetrical } \\
\text { (Quadrants II and IV) }\end{array}$ & $\begin{array}{l}\text { Mutually inhibitory } \\
\text { [Quadrant III] }\end{array}$ \\
\hline No 2 - No 8 & No 2 - No 20 & No $2-$ No 3 \\
\hline No3 - No 4 & No 2 - No 13 & No 2 - No 10 \\
\hline No 3 - No 6 & No 2 - No $?$ & No 3 - No 14 \\
\hline No 3 - No 8 & No 2 - No 18 & No 3 - No 2 \\
\hline No 3 - No 10 & No 2 - No 6 & No 3 - No 20 \\
\hline No 4 - No 8 & No 3 - No 13 & No 3 - No 18 \\
\hline No 4 - No 20 & No 3 - No ? & No 4 - No 14 \\
\hline No 4 - No 3 & No $4-$ No 2 & No 4 - No 18 \\
\hline No 4 - No 13 & No4 - No 10 & No 4 - No $?$ \\
\hline No 6 - No 4 & No 6 - No 20 & No 6 - No $?$ \\
\hline No 6 - No 10 & No 6 - No 8 & No 6 - No 13 \\
\hline No 6 - No 3 & No 6 - No 18 & No $?$ - No 20 \\
\hline No 7 - No 8 & No $?$ - No 14 & No 7 - No 6 \\
\hline No $?$ - No 10 & No 7 - No 13 & No 7 - No 4 \\
\hline No $?$ - No 18 & No $?$ - No 3 & No 8 - No 13 \\
\hline No 8 - No 10 & No $7-$ No 2 & No 8 - No 13 \\
\hline No 8 - No 4 & No 8 - No 20 & No $10-$ No 2 \\
\hline No 8 - No 2 & No 8 - No $?$ & No $10-$ No 20 \\
\hline No 8 - No 3 & No 8 - No 18 & No $10-$ No 13 \\
\hline No 8 - No 14 & No 8 - No 6 & No 13 - No 2 \\
\hline No $10-$ No 8 & No $10-$ No ? & No 13 - No 18 \\
\hline No $10-$ No 6 & No $10-$ No 18 & No 13 - No 10 \\
\hline No $10-$ No 3 & No $10-$ No 4 & No 13 - No 8 \\
\hline No $13-$ No 4 & No 13 - No 3 & No $14-$ No 4 \\
\hline No 13 - No 20 & No 13 - No 6 & No 14 - No 3 \\
\hline No 13 - No 14 & No $13-$ No $?$ & No 18 - No 10 \\
\hline No $14-$ No 8 & No $14-$ No 18 & No 18 - No 3 \\
\hline No $14-$ No 2 & No 14 - No 8 & No 18 - No 13 \\
\hline No $14-$ No 6 & No 18 - No 20 & No 20 - No 10 \\
\hline No 18 - No 2 & No 18 - No 6 & \\
\hline No 18 - No 14 & No 18 - No 4 & \\
\hline No18 - No 8 & No 20 - No 3 & \\
\hline No 18 - No $?$ & No $20-$ No $?$ & \\
\hline No $20-$ No 2 & No 20 - No 18 & \\
\hline No 20 - No 4 & No 20 - No 8 & \\
\hline \multirow[t]{2}{*}{ No 20 - No 6} & No 20 - No 13 & \\
\hline & No 20 - No 6 & \\
\hline
\end{tabular}

It is this capacity of interrelation and dependence among the members of a team that makes it a system, and not a simple group of components. The team is a qualitatively different entity, whose total value cannot be reflected by the sum of its individual values, but rather by a new dimension that emerges from the interaction among its components [14]. Indeed, according Teodorescu [15] "team games can be approached as situations in which to analyse group dynamics", in which the different positions of participants are translated into relation of strength among them. Each team is a micro-society with networks and relation-structures that relate the component elements to each other; making up "a complex and dynamic social micro-system" [1]. Therefore, studying the behaviour of soccer players requires more than the direct observation of the behaviour of one or more people in the same place. It needs the analysis of interaction systems of a wide range of people who are not limited to a single environment.

The motor action in soccer should be understood as a changing fabric of multiple interdependencies that bind the players to each other - whether they are or not in the same immediate context. The organisation of social relations is the key to analyse structural properties of the networks in which soccerplayers are immersed, and to detect emerging social phenomena, which have no existence at the individual level.

\section{CONCLUSIONS}

The polar coordinates technique has enabled us to produce a conceptual map of the motor relations among the members of a soccer team by comparing the different associations among players.

The opportunity to representing the relations among the player taken as the focal behaviour and the rest of players in the same conceptual map makes it clear that the action in soccer is not built up individually. The dyadic links can only be understood in connection with other dyads or parts of the network. Connections between two individuals are important by themselves and also as parts of the social networks to which they belong. Each link gives the 
member directs access to those individuals to whom their alter ego is related. Indirect links bind groups of relations which place the members of a network in a wider social system [16].

This paper has focused on the analysis of interactions among players in the attacking phase and has stressed the behaviour of the player in possession of the ball. The study should be followed up with the analysis of the attacking phase and the situations of co-operation and opposition during the game. This may help to reveal the manifestations of the game's inner logic.

\section{ADDRESS}

Carlos Lago Peñas

Facultad de CC. de la Educación

Universidad de Vigo

Av. Buenos Aires s/n

36002 Pontevedra

España

clagop@uvigo.es 


\section{REFERENCES}

1. Anguera, M.T. (1997) From prospective patterns in behaviour to joint analysis with a retrospective perspective. Presentation to Colloque Méthodologie d'Analyse des Interactions sociales. Paris: Université de la Sorbonne.

2. Anguera, M.T.; Losada, J.L. (1999) Reducción de datos en marcos de conducta mediante la técnica de coordenadas polares. In: M.T. Anguera (Ed.) Observación de conducta interactiva en contextos naturales: Aplicaciones. Barcelona: E.U.B, 163-188.

3. Bakeman, R. (1978) Untangling streams of behavior: Sequential analyses of observation data. In: G.P. Sackett (Ed.) Observing behavior. Data collection and analysis methods. Baltimore: University Park Press, 63-73.

4. Bakeman, R.; Gottman J.M. (1989) Observing behavior. An introduction to sequential analysis. Cambridge: Cambridge University Press.

5. Bakeman, R.; Quera, V. (1995) Analyzing interaction: Sequential analysis using SDIS and GSEQ. New York: Cambridge University Press.

6. Castellano, J. (2000) Observación y análisis de la acción de juego en el fútbol. Vitoria: Universidad del País Vasco.

7. Castelo, J. (1994) Futebol. Modelo técnico-táctico do jogo. Lisboa: Edições FMH.

8. Cochran, W.G. (1954) Some methods for strengthening the common test. Biometrics 10:417-451.

9. Garganta, J. (1997) Modelação táctica do jogo de futebol. Estudo da organização da fase ofensiva em equipas de alto rendimento. Tese de doutoramento. Porto: Universidade do Porto.

10. Hernández Mendo, A.; Anguera, M.T. (1998) Análisis de coordenadas polares en el estudio de las diferencias individuales de la acción de juego. In: M.P. Sánchez, M.A. Quiroga (Eds.) Perspectivas actuales de la investigación psicológica de las diferencias individuales. Madrid: Centro de Estudios Ramón Areces, 84-88.

11. Lago Peñas, C. (2000) La acción motriz en los deportes de equipo despacio común y participación simultánea. A Coruña: Universidade de A Coruña.

12. Sackett, G.P. (ed.) (1978) Observing behaviour. Data collection and analysis methods. Vol. II. Baltimore: University Park Press.

13. Sackett, G.P. (1980) Lag sequential analysis as a data reduction technique in social interaction research. In: D.B. Sawin, R.C. Hawkins, L.O. Walker and J.H. Penticuff (Eds.) Exceptional infant. Psychosocial risks in infant-environment transactions. New York: Brunner/Mazel, 300-340.

14. Serrano Sánchez, J.A. (1996). Acerca de una confrontación de los problemas de estatuto científico entre la Educación Física y la Praxiología Motriz. Praxiología Motriz 1:65-109.

15. Teodorescu, L. (1984) Problemas de teoria e metodologia nos jogos desportivos. Lisboa: Livros Horizonte. 